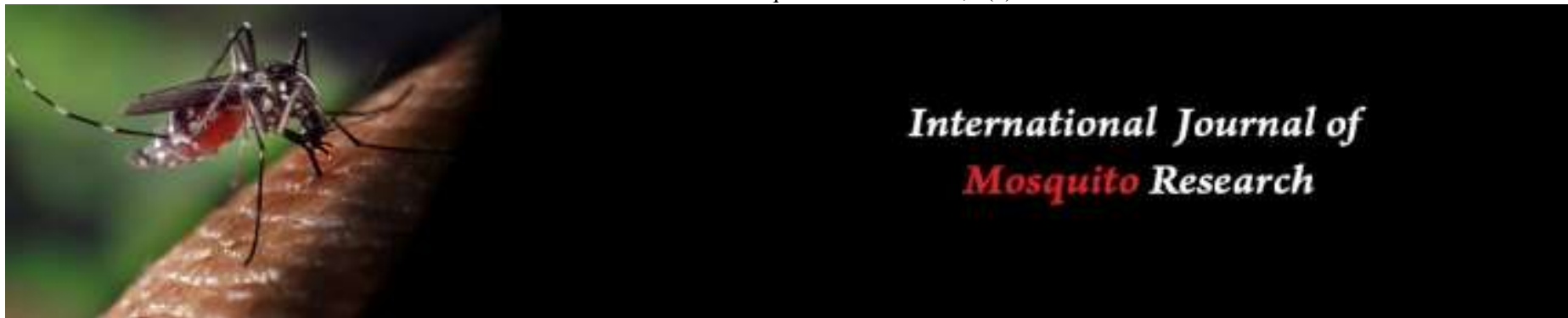

ISSN: 2348-5906

CODEN: IJMRK2

IJMR 2021; 8(5): 20-24

(C) 2021 IJMR

www.dipterajournal.com

Received: 12-07-2021

Accepted: 15-08-2021

Suresh Chand Kaushik

154 A, Express view Apartment,

Sector 93, Noida, Uttar Pradesh, India

Sukhvir Singh

Gali no. 37/7, Harijan Basti,

Jharoda Majra, Part II

Extension, Buradi Delhi,

Delhi, India
Corresponding Author: Suresh Chand Kaushik 154 A, Express view Apartment, Sector 93, Noida, Uttar Pradesh, India

\section{Longitudinal studies on seasonal fluctuation of Aedes aegypti in Delhi, India due to climatic conditions}

\author{
Suresh Chand Kaushik and Sukhvir Singh
}

DOI: https://doi.org/10.22271/23487941.2021.v8.i5a.558

\begin{abstract}
Unplanned urbanization and informal settlements create ideal breeding habitats for Aedes species. India's rapid population growth and increased rural-urban movement has augmented the spread of dengue and resurgence of chikungunya. Ae. Aegypti is the vector of arboviruses answerable for significant sicknesses like dengue, dengue hemorrhagic fever and Chikungunya. The Studies on seasonal fluctuation of Ae. Aegypti were undertaken in Shahadara South, Rohini and Najafgarh. Month-wise House Index (HI), Container Index (CI) and Breteau Index (BI) of Shahdara, Rohini \& Najafgarh were recorded during $2016 \& 2018$. The HI, CI and BI in Najafgarh (SDMC) varied from 0.0-5.39, 0.0-5.16\& 0.0-9.07 respectively during 2016 and from 0.0-4.1, 0.0-9.6 and 0.0-4.3 respectively during 2018. The HI, CI and $\mathrm{BI}$ in Rohini (NDMC) varied from 0.0-3.1, 0.0-3.7 \& 0.0-5.3 respectively during 2016 and from $0.0-4.1$, 0.0-9.6 and 0.0-4.3 respectively during 2018. The HI, CI and BI in Shahadara (EDMC) varied from 0.05$4.9,0.04-6.3 \& 0.5-16.7$ respectively during 2016 and from $0.0-2.6,0.0-5.1 \& 0.0-14.0$ respectively during 2018.
\end{abstract}

Keywords: Ae. Aegypti, House Index (HI), Container Index (CI) and Breteau Index (BI)

\section{Introduction}

Mosquitoes transmit diseases of public health importance such as dengue, chikungunya, malaria, filariasis, zika, etc., thus presenting a threat to human health. For the last few years, annually more than one lakh cases of dengue infections occur in India resulting in substantial rates of mortality and morbidity ${ }^{[1]}$. At the same time, arbovirus transmission has become one of the major global public health issues in the past decades. Yellow fever virus, dengue virus (DENV), chikungunya virus (CHIKV) and zika virus (ZIKV) are transmitted by mosquitoes in tropical and sub-tropical regions [2]. Annually, about 390 million people worldwide are estimated to be affected by dengue virus (DENV), causing more illness and death than any other virus transmitted by arthropods ${ }^{[3]}$. Unplanned urbanization and informal settlements create ideal breeding habitats for Aedes. India's rapid population growth and increased ruralurban movement has augmented the spread of dengue and resurgence of chikungunya ${ }^{[4]}$.

The spread of vector borne sicknesses is controlled by complex segment, ecological and social elements. Worldwide travel and exchange, impromptu urbanization and natural difficulties, for example, environmental changes can effect on pathogen transmission season longer or progressively extreme or making sicknesses develop in nation where they were already obscure. One million or more lose their lives because of mosquito chomps each year with the greater part because of intestinal sickness. 2.5 billion Individuals are in danger of contracting dengue fever, a viral sickness broadly spread in tropical locales.

Tropical zones are generally defenseless against parasitic disease and the danger of contracting arthropod borne diseases has expanded because of environmental change and strengthening globalization. Ae. Aegypti is the vector of arboviruses answerable for significant sicknesses like dengue, dengue hemorrhagic fever and Chikungunya.

It is very much essential to study the correlation between prevalence of dengue vectors and different climatic parameters to guide the state as well as national program for developing an early warning system for outbreaks of dengue in Delhi NCR. Additional research studies are wanted in Delhi NCR for better understanding the seasonal prevalence of Aedes mosquitoes. 
Climate changes have been reported to affect the biology and behavior of vectors allowing them to develop higher competence for dengue transmission. This supports the necessity of entomological surveillance to assess and predict the abundance of vectors and possibilities of occurrence of dengue.

\section{Materials and methods}

The immature stages of Aedes mosquito were collected with the help of ladle and pipette from Shahadara South, Rohini and Najafgarh. Localities throughout the year to know House, Container and Breteau indices. The material was brought to the laboratory for rearing and identification upto species level. The maximum House, Container and Breteau indices were recorded for August, 2018. The Studies on seasonal fluctuation of Ae. Aegypti were undertaken in Shahadara South, Rohini and Najafgarh. Month-wise HI, CI and BI of Shahdara, Rohini \& Najafgarh were recorded during 2016 \& 2018. Climatic data was taken from India Meteorological Department, Regional Meteorological Centre Lodhi Road Delhi to study Dengue transmission during 2016 (Table - 1) and 2018 (Table - 2).

\section{Results}

Seasonal Prevalence in Najafgarh (South Delhi Municipal Corporation) during 2016 and 2018 The HI, CI and BI in Najafgarh (SDMC) varied from 0.0-5.39, 0.0-5.16\& 0.0-9.07 respectively during 2016. The maximum House index was recorded in August, 2016 while the maximum CI and BI were recorded in July, 2016. The HI, CI and BI indices were minimum during the months of January, February and April, 2016 (Figure - 1). The HI, CI and BI in Najafgarh (SDMC) varied from 0.0-4.1, 0.0-9.6 and 0.0-4.3 respectively during 2018. The maximum HI, CI and BI indices were recorded for August, 2018. The HI, CI and BI indices were minimum during the months of January, March and November, 2018 (Figure-2).

Seasonal Prevalence in Rohini (North Delhi Municipal Corporation) during 2016 and 2018 The HI, CI and BI in Rohini (NDMC) varied from 0.0-3.1, 0.0-3.7 \& 0.0-5.3 respectively during 2016. The maximum HI, CI and BI index was recorded for August, 2016 while the maximum CI and BI indices were recorded for July, 2016 (Figure - 3). The HI, CI and BI were minimum during the months of January, February, April and November, 2016.The HI, CI and BI in Najafgarh (SDMC) varied from 0.0-4.1, 0.0-9.6 and 0.0-4.3 respectively during 2018. The maximum HI, CI and BI indices were recorded for August, 2018. The HI, CI and BI were minimum during the months of January, March and November, 2018 (Figure -4).

Seasonal Prevalence in Shahdara (East Delhi Municipal Corporation) during 2016 and 2018 The HI, CI and BI in Shahadara (EDMC) varied from 0.05-4.9, 0.04-6.3 \& 0.5-16.7 respectively during 2016. The maximum HI, CI and BI were recorded for August, 2016. The HI, CI and BI were minimum during the months of January, 2016 (Figure - 5). The HI, CI and BI in Shahdara (EDMC) varied from 0.0-2.6, 0.0-5.1 \& 0.0-14.0 respectively during 2018. The maximum HI was recorded for September, 2018 while the maximum CI and BI indices were recorded for August, 2018. The HI, CI and BI were minimum during the months of January, February, April and November, 2018 (Figure -6)

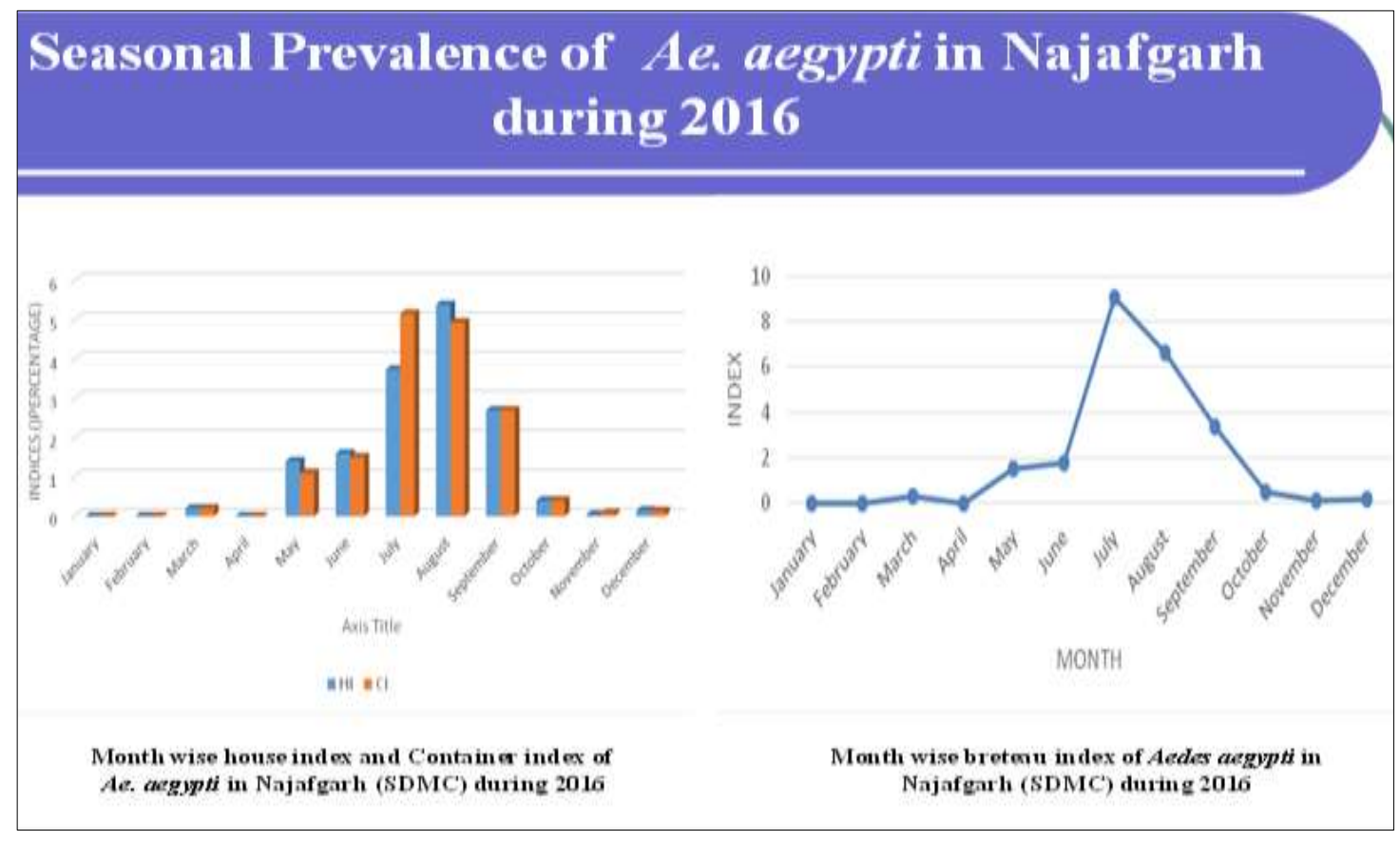

Fig 1: Seasonal Prevalence of Ae. Aegypti in Najafgarh during 2016 


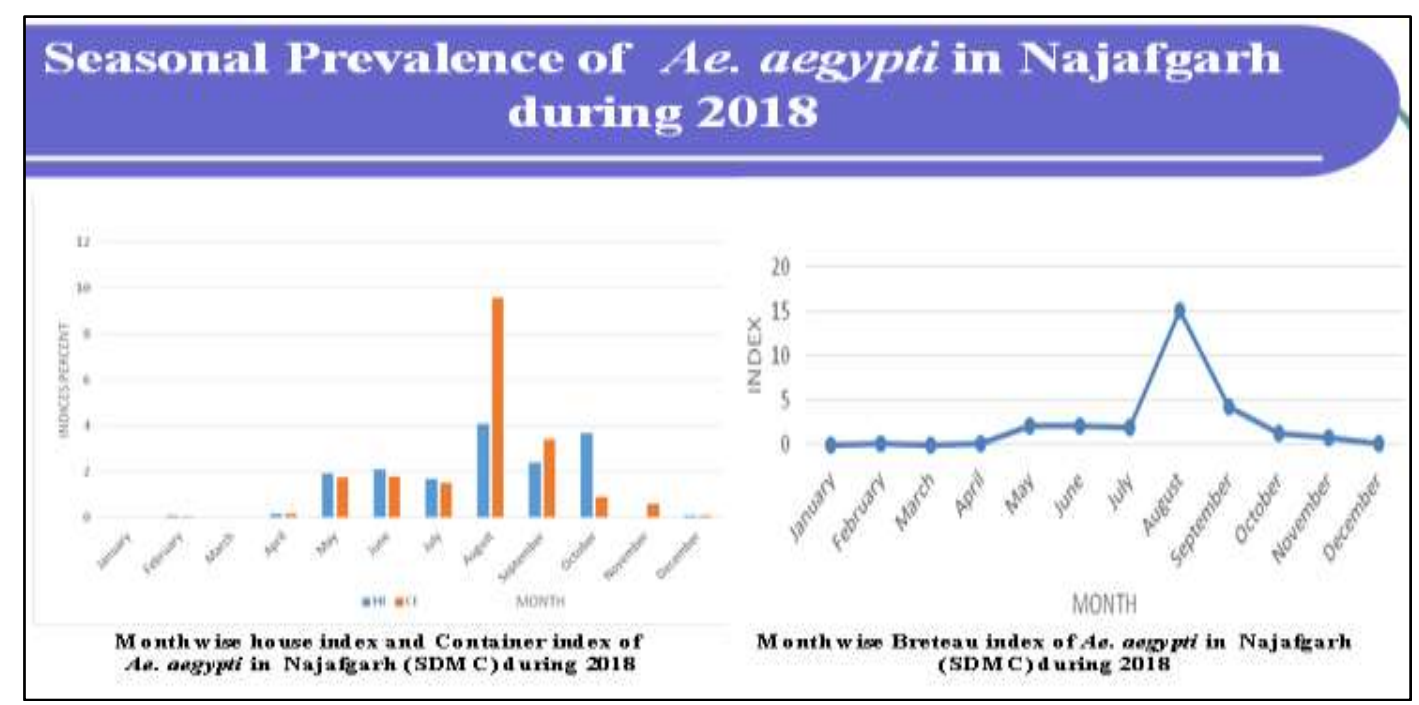

Fig 2: Seasonal Prevalence of Ae. Aegypti in Najafgarh during 2018

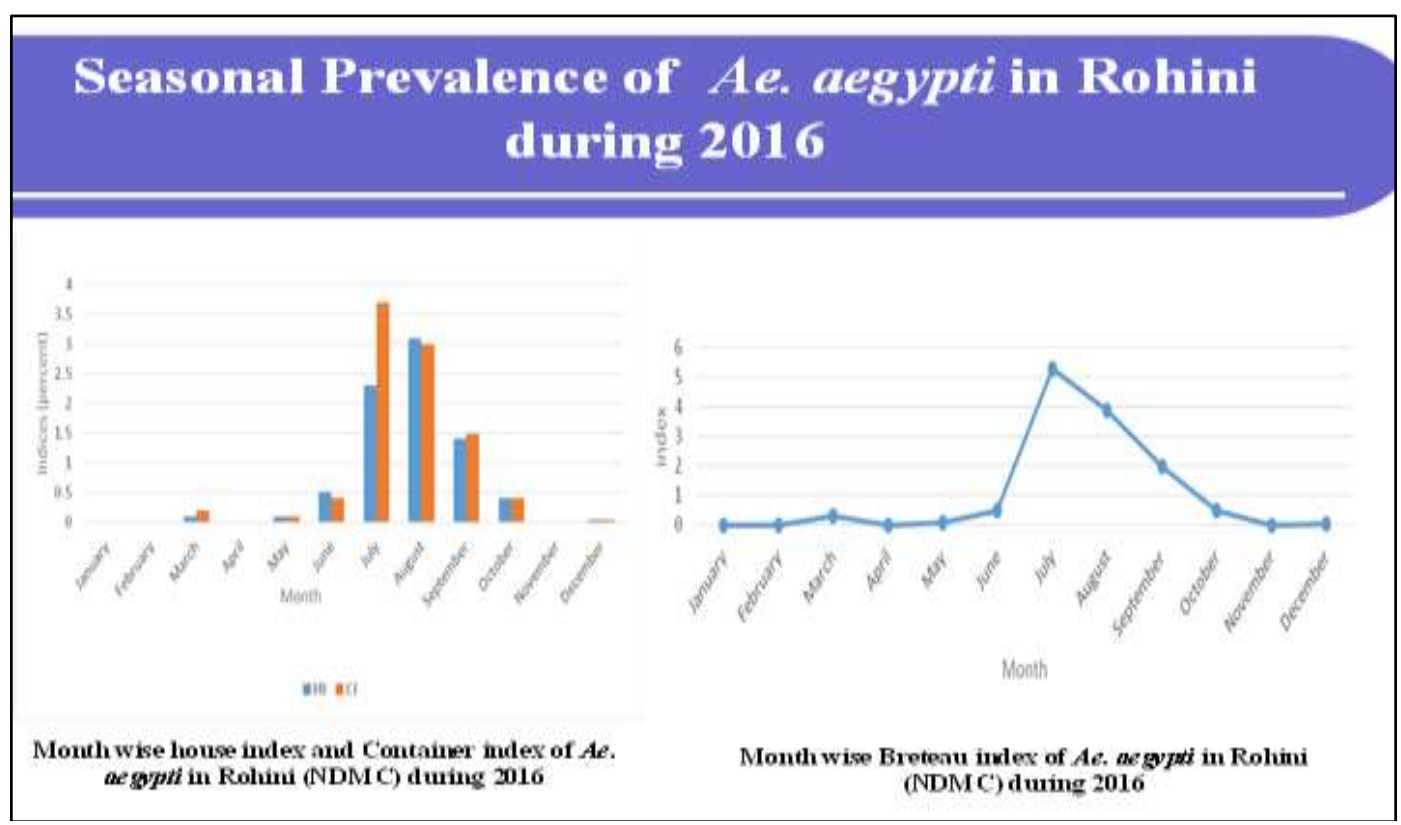

Fig 3: Seasonal Prevalence of Ae. Aegypti in Rohini during 2016

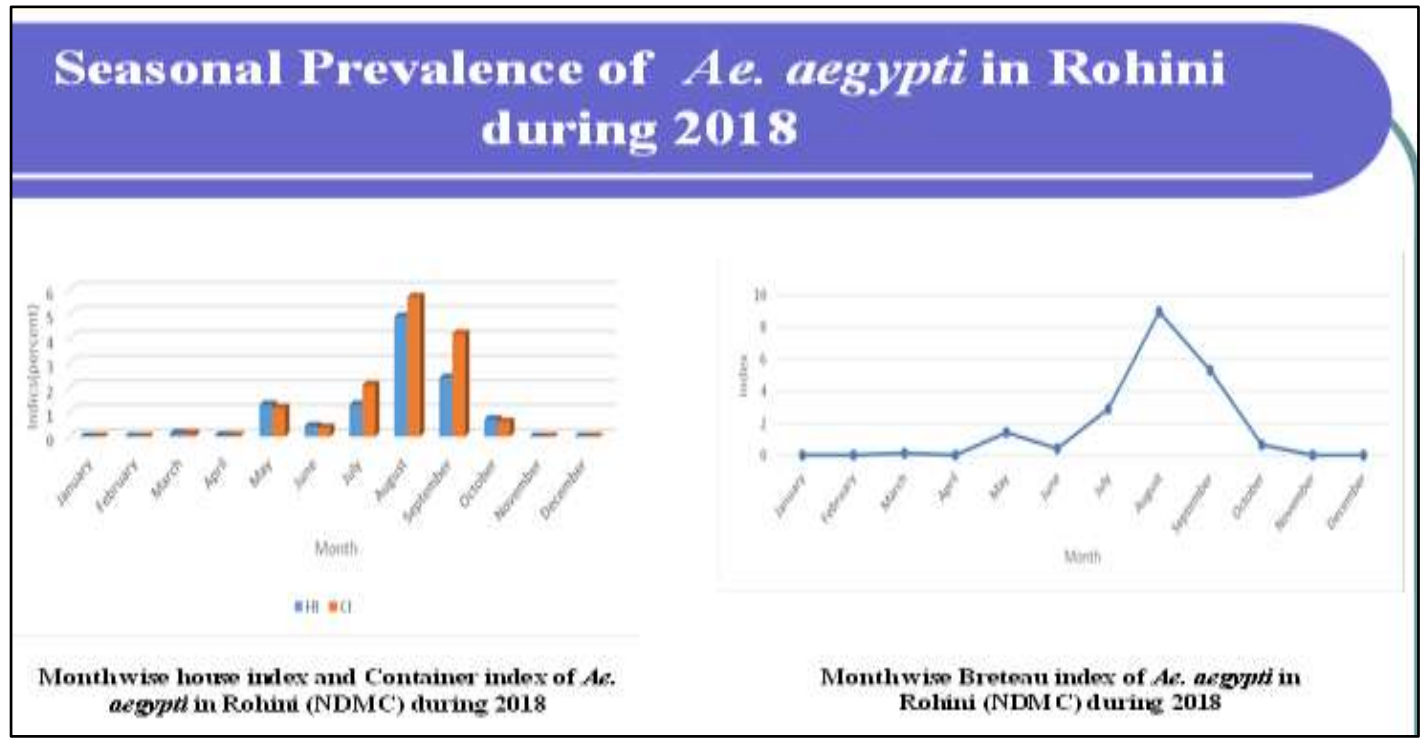

Fig 4: Seasonal Prevalence of Ae. Aegypti in Rohini during 2018 


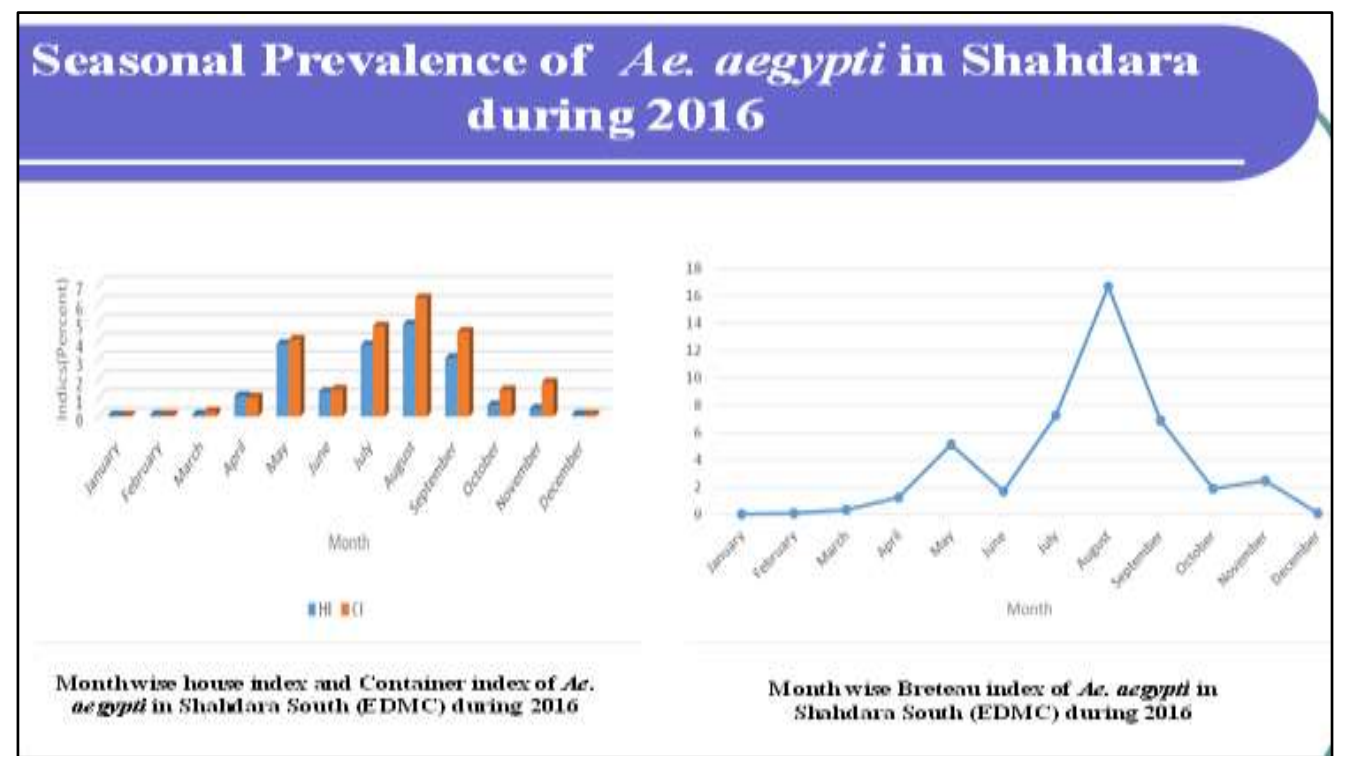

Fig 5: Seasonal Prevalence of Ae. Aegypti in Shahdara during 2016

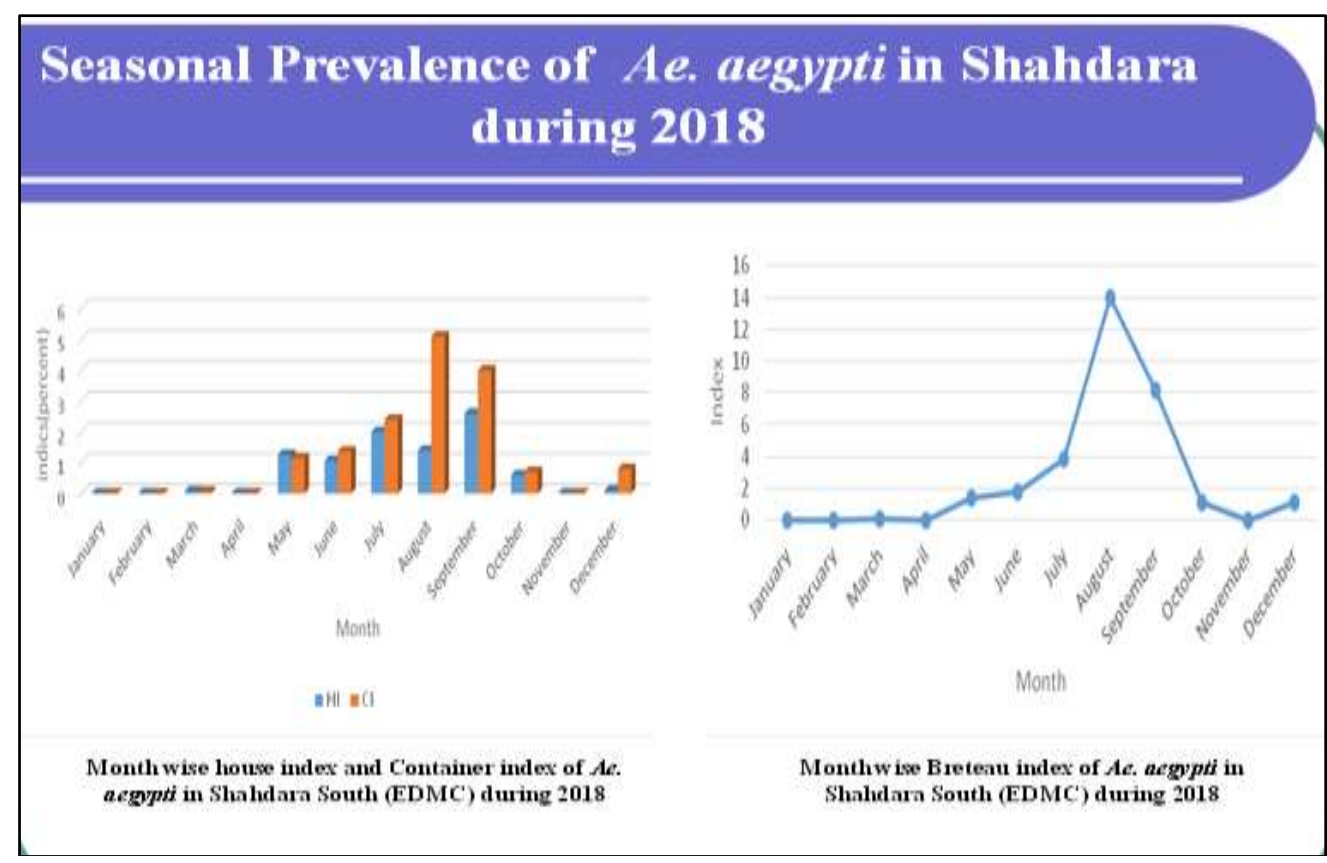

Fig 6: Seasonal Prevalence of Ae. Aegypti in Shahdara during 2018

Table 1: Month wise dengue cases and meteorological data of Delhi during 2016

\begin{tabular}{|c|c|c|c|c|c|c|}
\hline Month & \multicolumn{2}{|c|}{ Temperature $\left(^{\mathbf{0}} \mathbf{C}\right)$} & DTR $\left({ }^{\mathbf{} C}\right)$ & Rainfall $(\mathbf{m m})$ & RH (\%) & Dengue cases \\
\hline & Max. & Min. & & & & \\
\hline January & 21.3 & 09.1 & 12.5 & 0 & 70.3 & 0 \\
\hline February & 25.7 & 10.9 & 14.8 & 001.3 & 49.2 & 0 \\
\hline March & 31.5 & 17.3 & 14.2 & 32.0 & 44.9 & 2 \\
\hline April & 38.0 & 23.4 & 14.6 & 000.0 & 23.1 & 5 \\
\hline May & 40.1 & 26.8 & 13.3 & 024.3 & 36.4 & 6 \\
\hline June & 39.5 & 28.7 & 10.8 & 034.5 & 47.3 & 15 \\
\hline July & 34.5 & 27.2 & 7.2 & 292.5 & 74.5 & 91 \\
\hline August & 34.5 & 26.8 & 7.7 & 122.7 & 72.1 & 652 \\
\hline September & 35.0 & 25.7 & 9.3 & 075.0 & 57.1 & 1362 \\
\hline October & 34.2 & 20.6 & 13.6 & 002.0 & 50.3 & 1517 \\
\hline November & 29.2 & 12.8 & 16.4 & 000.0 & 52.4 & 655 \\
\hline December & 4.2 & 09.5 & 14.7 & 000.0 & 64.1 & 126 \\
\hline
\end{tabular}


Table 2: Month wise dengue cases and meteorological data of Delhi during 2018

\begin{tabular}{|c|c|c|c|c|c|c|}
\hline \multirow{2}{*}{ Month } & \multicolumn{2}{|c|}{ Temperature (0C) } & \multirow{2}{*}{$\operatorname{DTR}(\mathbf{0 C})$} & \multirow{2}{*}{ Rainfall (in mm) } & \multirow{2}{*}{ Relative humidity (\%) } & \multirow{2}{*}{ Dengue cases } \\
\hline & Maximum & Minimum & & & & \\
\hline January & 20.8 & 9.2 & 11.6 & 11 & 54 & 5 \\
\hline February & 24.7 & 11.8 & 12.9 & 16 & 52 & 4 \\
\hline March & 31.3 & 16.8 & 14.5 & 16 & 37 & 9 \\
\hline April & 38.2 & 24.5 & 13.7 & 15 & 21 & 8 \\
\hline May & 42.3 & 29.8 & 12.5 & 07 & 18 & 8 \\
\hline June & 42.4 & 32.0 & 10.4 & 19 & 28 & 24 \\
\hline July & 37.6 & 29.7 & 7.9 & 86 & 54 & 49 \\
\hline August & 35.4 & 28.2 & 7.2 & 76 & 62 & 108 \\
\hline September & 35.0 & 26.3 & 8.7 & 49 & 57 & 889 \\
\hline October & 28.6 & 23.2 & 5.4 & 2 & 37 & 2245 \\
\hline November & 23.5 & 17.9 & 5.6 & 3 & 32 & 2813 \\
\hline December & 23.5 & 12.5 & 11 & 5 & 39 & 922 \\
\hline
\end{tabular}

\section{Discussion}

Our study on seasonal prevalence on Ae. Aegypti in Delhi and NCR revealed that larval indices of dengue vector were more in transmission season which is consistent with the studies done in Thailand ${ }^{[5]}$. Abiotic factors play vital role in the vector breeding and contribute to the increase in larval indices [6].

Our studies showed that the HI was 5.39,3.1 and 4.9 in Nazfgarh, Rohini and Shahadara respectively in August, 2016 which were lower than $10 \%$ in different areas which is consistent with the studies done in Malaysia ${ }^{[7]}$ but different with the study done in Tauru Village of NCR in 1996 having $33.3 \% \mathrm{HI}, 21.0 \% \mathrm{CI}$ and $40.0 \% \mathrm{BI}$ respectively ${ }^{[8]}$. The gradual increase in number of cases from July 2016 to September 2016 was due to heavy rainfall which increased the number of potential containers during post monsoon season due to rain in preceding months.

Temperature and dengue cases were found correlated which is consistent with our study in which the upsurge in cases of dengue was observed with the gradual escalation in diurnal temperature Range (DTR from) July 2016 to October $2016^{(9}$ 10) but DTR fluctuated inspite of increasing of dengue cases from July 2018 to October 2018.

Two of the main abiotic factors temperature and relative humidity are mainly responsible for the transmission of dengue ${ }^{[11]}$, which is consistent with the meteorological data taken in 2016 and 2018. Small seasonal fluctuations due to climatic change has increased the incidence of mosquito borne disease. Hence, climatic change also affect dengue transmission for which better knowledge of vector bionomics is imperative to predict the prevalence of Ae. Aegypti.

\section{Conclusion}

From the study it is concluded that seasonal prevalence on $A e$. Aegypti in Delhi and NCR revealed that larval indices of dengue vector were more in transmission season from July to September. This was due to heavy rainfall which increased the number of potential containers during post monsoon season. Abiotic factors mainly temperature and relative humidity are responsible for the transmission of dengue during post monsoon season. It is important to have knowledge of vector bionomics to predict the prevalence of Ae. Aegypti for dengue transmission. There is need to gear up control measures used in public health for the prevention and control of dengue outbreak.

\section{References}

1. Bharati M, Saha D. Multiple insecticide resistance mechanisms in primary dengue vector, Aedes aegypti (Linn.) from dengue endemic districts of sub-Himalayan
West Bengal, India PloS one 2018;13(9):e0203207.

2. Kamgang B, Yougang AP, Tchoupo M, Riveron JM, Wondji C. Temporal distribution and insecticide resistance profile of two major arbovirus vectors Aedes aegypti and Aedes albopictus in Yaoundé, the capital city of Cameroon. Parasites \& Vectors 2017;10(1):1-9.

3. Garcia GDA, David MR, Martins ADJ, Maciel-deFreitas R, Linss JGB, Araújo SC et al. The impact of insecticide applications on the dynamics of resistance: The case of four Aedes aegypti populations from different Brazilian regions. PLoS Neglected Tropical Diseases 2018;12(2):e0006227.

4. Sharma R, Kumari R, Srivastava P, Barua K, Chauhan L. Emergence of dengue problem in India - A public health challenge. Journal Communicable Diseases 2014;46(2):17-45.

5. Thavara U, Tawatsin A, Chansang C, Kong-ngamsuk W, Paosriwong S, Boon-Long J et al. Larval occurrence, oviposition behavior and biting activity of potential mosquito vectors of dengue on Samui Island, Thailand. Journal of Vector Ecology 2001;26(2):172-180.

6. Chakravarti, Kumaria R. Eco-epidemiological analysis of dengue infection during outbreak of dengue fever, India. Virology Journal 2005;2:32.

7. Sulaiman S, Pawanchee ZA, Arifin Z, Wahab A Relationship between breteau and house indices and case of dengue/ DHF in Kuala Lampur, Malaysia. Journal of The American Mosquito Control Association 1996;12(3):494-496.

8. Katyal R, Kumar K, Gill KS. Breeding of Aedes aegypti and its impact on Dengue/DHF in rural areas of NCR. Dengue Bulletin 1997;21:93-95.

9. Pinto E, Coelho M, Oliver L, Massad E. The influence of climate variables on dengue in Singapore. Int J Environ Health Res 2011;21:415-426.

10. Hales S, Weinstein P, Souares Y, Woodward A. El Nino and the dynamics of vector borne disease transmission. Environ Health Perspect 1999;107:99-102.

11. Earnest A, Tan SB, Wilder-Smith A. Meteorological factors and El Nino Southern Oscillation are independently associated with dengue infections. Epidemiol Infect 2012;140:1244-125. 